\title{
A Study of Lipid Profile in Diabetic Patients
}

\author{
Author \\ Rosy Khandelia \\ Demonstrator, Dept of Pathology, Gauhati Medical College, Guwahati, Assam, India \\ Corresponding Author \\ Dr Rosy Khandelia \\ Demonstrator, Department of Pathology, Gauhati Medical College, \\ Guwahati, Assam, India 781005 \\ Phone Number 07896614841. Email: rosykhandelia12345@gmail.com
}

\begin{abstract}
Background: Dyslipidemia is one of the common disorders seen in most of the diabetes patients. Objective: To study the lipid profile in patients with diabetes mellitus.

Methods: The study was carried out at a diagnostic and research centre for a period of one year. The study included 100 diabetic patients and 100 healthy subjects.Their serum samples were assessed for fasting blood glucose, total cholesterol, triglycerides, low density lipoprotein(LDL) cholesterol and high density lipoprotein $(H D L)$ cholesterol by using standard biochemical methods after taking informed consent.

Results: Out of 100 diabetic patients 45 (45\%) were males and 55 (55\%) were females. 75 patients presented with type 2 diabetes mellitus(DM) and 25 patients with type 1 diabetes mellitus. Maximum number of patients were in age group of 20-30 years in type-1 and 45-65 years in type-2 diabetes mellitus. $85.3 \%$ of type 2 DM patients showed high serum cholesterol level, while only $32 \%$ of the type 1 DM patients showed high serum cholesterol level. 80\% of type 2 DM patients showed high serum triglyceride level, while $60 \%$ of type 1 DM subjects showed high triglyceride level. Serum LDL level was high in $48 \%$ of type 2 DM patients, while only $16 \%$ of type $1 \mathrm{DM}$ patients showed higher value. $40 \%$ of type $1 \mathrm{DM}$ patients showed low $1<40$ $\mathrm{mg} / \mathrm{dl}$ ) serum HDL value while all patients of type 2 had low serum HDL level.

Conclusion: The frequencies of the high cholesterol, high TG, high LDL with low HDL levels were higher in the diabetic group, thus indicating that diabetic patients were more prone for dyslipidemia, which is a major risk factor for cardiovascular disorders.
\end{abstract}

Keywords-dyslipidemia, diabetes mellitus, serum cholesterol, serum LDL, serum HDL, serum triglyceride.

\section{INTRODUCTION}

Diabetes mellitus (DM) is the most common metabolic disorder affecting the people worldwide. Even though diabetes has been known since antiquity, only in the last few decades new discoveries have provided great hopes to minimize morbidity and mortality. Dyslipidemia is commonly seen in diabetes. Type $2 \mathrm{DM}$ is one of the most common secondary causes of hyperlipidemia. The relationship between hyperlipidemia and vascular complication of diabetes has long been of interest because both tend to occur with greater frequency in Type 2 DM. Insulin resistance and obesity combine to cause dyslipidemia and hyperglycemia and 
hyperlipidemia have additive cardiovascular risk. Hence identification, critical evaluation, and followup of serum lipid profile in Type 2 DM continue to be important. ${ }^{1}$ The prevalence of dyslipidemia in diabetes mellitus is $95 \% .^{2}$ The dyslipidemia is a major risk factor for Coronary Heart Disease. ${ }^{3}$ The cardiovascular disease is a cause of morbidity and mortality in patients with diabetes mellitus because of disturbance in lipoproteins i.e. serum triglycerides (TC) 69\%, serum cholesterol 56.6\%, Low Density Lipoprotein cholesterol (LDL) 77\% and High Density Lipoprotein cholesterol (HDL) $71 \%$. ${ }^{4,5}$ The purpose of the study was to observe the lipid profile in patient of diabetics mellitus.

\section{MATERIALS AND METHODS}

A prospective study was done in a diagnostic and research centre for a period of one year. A total 100 patients with diabetes mellitus were evaluated for lipid profile.100 normal healthy volunteers between age group of 13-75 years were selected for control study. The detail history was taken, relevant clinical examination and routine investigations were performed. An informed consent was taken from every patient after full explanation of the procedure. Every patient was advise for at least 12-14 hours overnight fasting and $5 \mathrm{ml}$ venous blood was collected in a disposable syringe on next morning (before breakfast) for the serum lipid profile and fasting blood sugar.

\section{RESULTS AND OBSERVATIONS}

A total 100 patients with diabetes mellitus were evaluated for lipid profile. Out of 100 diabetic patients $45(45 \%)$ were males and 55 (55\%) were females. 75 patients presented with type 2 diabetes mellitus and 25 patients with type 1 diabetes mellitus. Maximum number of patients were in age group of 20-30 years in type-1 DM \& 45-65 years in type-2 DM. $85.3 \%$ of type 2 DM patients showed high serum cholesterol level, while only $32 \%$ of the type1 DM patients showed high serum cholesterol level. In control group all persons had normal serum cholesterol level (Table 1).
TABLE - 1 Distribution of the controls and patients according to their serum cholesterol level

\begin{tabular}{|l|c|c|c|}
\hline $\begin{array}{l}\text { Serum } \\
\text { cholesterol level }\end{array}$ & Control & $\begin{array}{c}\text { Type 1 } \\
\text { DM }\end{array}$ & $\begin{array}{c}\text { Type 2 } \\
\text { DM }\end{array}$ \\
\hline$<150$ & 75 & 07 & 00 \\
\hline $151-250$ & 25 & 10 & 11 \\
\hline $251-300$ & 00 & 08 & 39 \\
\hline $301-350$ & 00 & 00 & 08 \\
\hline $351-400$ & 00 & 00 & 17 \\
\hline Total & 100 & 25 & 75 \\
\hline
\end{tabular}

$60 \%$ of type $1 \mathrm{DM}$ patients showed high serum triglyceride level (>150mg/dl), while $80 \%$ of type 2 DM subjects showed high triglyceride level (Table 2).

TABLE 2 Distribution of the controls and patients according to their serum triglyceride level.

\begin{tabular}{|l|c|c|c|}
\hline $\begin{array}{l}\text { Serum } \\
\text { triglyceride level }\end{array}$ & Control & $\begin{array}{c}\text { Type 1 } \\
\text { DM }\end{array}$ & $\begin{array}{c}\text { Type 2 } \\
\text { DM }\end{array}$ \\
\hline$<150$ & 100 & 10 & 15 \\
\hline $150-199$ & 00 & 07 & 17 \\
\hline $200-499$ & 00 & 08 & 31 \\
\hline$>500$ & 00 & 00 & 12 \\
\hline Total & 100 & 25 & 75 \\
\hline
\end{tabular}

Serum LDL level was high (>160 mg/dl ) in $48 \%$ of type 2 DM patients, while only $16 \%$ of type $1 \mathrm{DM}$ patients showed higher value (Table 3 ).

TABLE-3 Distribution of the controls and patients according to their serum LDL level.

\begin{tabular}{|l|c|c|c|}
\hline Serum LDL level & Control & $\begin{array}{c}\text { Type 1 } \\
\text { DM }\end{array}$ & $\begin{array}{c}\text { Type 2 } \\
\text { DM }\end{array}$ \\
\hline$<130$ & 90 & 03 & 20 \\
\hline $130-159$ & 10 & 18 & 19 \\
\hline$>160$ & 00 & 04 & 36 \\
\hline Total & 100 & 25 & 75 \\
\hline
\end{tabular}

$40 \%$ of type $1 \mathrm{DM}$ patients showed low $(<40 \mathrm{mg} / \mathrm{dl})$ serum HDL value while all patients of type $2 \mathrm{DM}$ had low serum HDL level (Table 4).

TABLE-4 Distribution of the controls and patients according to their serum HDL level.

\begin{tabular}{|l|c|c|c|}
\hline $\begin{array}{l}\text { Serum HDL } \\
\text { level }\end{array}$ & Control & $\begin{array}{c}\text { Type 1 } \\
\text { DM }\end{array}$ & $\begin{array}{c}\text { Type 2 } \\
\text { DM }\end{array}$ \\
\hline$<40$ & 25 & 10 & 75 \\
\hline$>=60$ & 75 & 15 & 00 \\
\hline Total & 100 & 25 & 75 \\
\hline
\end{tabular}

\section{DISCUSSION}

Dyslipidemia is one of the common disorder seen in most of the diabetes patients. Dyslipidemias make diabetics prone to develop coronary heart diseases 
and other complications of atherosclerosis. In our study majority of type $2 \mathrm{DM}$ patients $(85.3 \%)$ showed high serum cholesterol level, while $32 \%$ of the type 1 DM patients showed high serum cholesterol level. According to the CDC, 97\% of adults with diabetes have one or more lipid abnormalities while the prevalence of diabetic dyslipidemia varies from $25 \%$ to $60 \%$ in other studies. ${ }^{6}$ This variation in prevalence may be due to differences in body mass index and possibly genetic variation. $60 \%$ of type $1 \mathrm{DM}$ patients showed high serum triglyceride level, while $80 \%$ of type $2 \mathrm{DM}$ subjects showed high triglyceride level. This was in accordance to the study done by G. D. Bhambhani et al where serum LDL level was high in $78 \%$ of type $2 \mathrm{DM}$ patients, while only $19 \%$ of type $1 \mathrm{DM}$ patients showed higher value. $^{7}$

\section{CONCLUSION}

From this study, it is evident that all the lipid fractions are elevated in patient with diabetic mellitus when compared to healthy controls suggesting that DM has a real impact on lipid metabolism. Early screening of diabetic patients for dyslipidemia and early intervention is required to minimize the risk of cardiovascular diseases.

\section{REFERENCES}

1. Hanish R Jain, V Shetty, G S Singh, S Shetty. A Study of Lipid Profile in Diabetes Mellitus.International Journal of Scientific Study.2016;4(2): 56-60

2. Chattanda SP, Mgonda YM. Diabetic dyslipidemia among diabetic patients attending specialized clinics in Dar es Salaam. Tanzania. Med J. 2008;23(1):08-11.

3. Krishna P, Roopakala, Prasanna KM. Dyslipidemia in type 1 diabetes mellitus in the young. Int $\mathrm{J}$ Diabetes Dev Ctries. 2005;25(4):110-2.

4. Khan SR, Ayub N, Nawab S, Shamsi TS. Triglyceride profile in dyslipidemia of type 2 diabetes mellitus. J Coll Physicians Surg Pak. 2008;18(5):270-3.
5. Gadi R, Samaha FF. Dyslipidemia in type 2 diabetes mellitus. Curr Diabetes Rep. 2007;7(3):228-34.

6. Hidron AI, Edwards JR, Patel J, Horan TC, Sievert DM, Pollock DA. NHSN annual update: antimicrobial-resistant pathogens associated with healthcare-associated infections: annual summary of data reported to the National Healthcare Safety Network at the Centers for Disease Control and Prevention, 2006-2007. Infect Control Hosp Epidemiol. 2008;29(11):996-1011.

7. G. D. Bhambhani, Rutu G. Bhambhani, Nilesh Chandradityasinh Thakor. Lipid profile of patients with diabetes mellitus: a cross sectional study. International Journal of Research in Medical Sciences. 2015;3(11): 3292-3294. 